\title{
Pattern of adverse drug reactions into psychiatric patients
}

\author{
Sandip Barvaliya ${ }^{1}$, Jigar R. Panchal ${ }^{1 *}$, Mira K. Desai ${ }^{1}$, Minakshi Parikh ${ }^{2}$
}

${ }^{1}$ Department of Pharmacology,

${ }^{2}$ Department of Psychiatry,

BJ Medical College,

Ahmedabad, Gujrat, India

Received: 05 March 2019

Accepted: 12 April 2019

*Correspondence to:

Dr. Jigar R. Panchal,

Email:

doc.jigarpanchal@gmail.com

Copyright: (C) the author(s), publisher and licensee Medip Academy. This is an openaccess article distributed under the terms of the Creative Commons Attribution NonCommercial License, which permits unrestricted noncommercial use, distribution, and reproduction in any medium, provided the original work is properly cited.

\begin{abstract}
Background: To analyse adverse drug reactions (ADRs) reported in patients prescribed psychiatric medications at tertiary care hospital.

Methods: ADRs reported in psychiatric patients between January 2011 to June 2017 were analyzed for demographic details, causal drugs, system organ classification, causality assessment (WHO-UMC criteria and Naranjo's scale), preventability (Modified Schumock and Thorton's criteria) and severity (Hartwing scale).

Results: A total 4368 ADRs were reported during study period, out of which 658 $(15.06 \%)$ were in psychiatric patients. The mean age of patients was $38 \pm 13.34$ years and men $(57.3 \%)$ were most commonly affected than women $(42.7 \%)$. The most common causal drug groups were antidepressants $(29.48 \%)$ followed by antipsychotics $(23.12 \%)$ which include drug fluoxetine $(33.9 \%)$ and olanzapine (34.3\%) respectively. The most common system involved were central nervous system $(32.8 \%)$ followed by gastrointestinal system (22.8\%). Most of ADRs $(42.7 \%)$ were observed after one month of therapy and showed possible (77\%) causal relation with drug therapy. Majority of ADRs (77.4\%) were not preventable and mild in nature $(83.3 \%)$.

Conclusions: ADRs are commonly seen in psychiatric patients. Hence, their monitoring and assessment in these patients who require multidrug and long-term therapy may help improve patient management.
\end{abstract}

Keywords: Antidepressants, Antipsychotics, ADRs, Psychiatric, Pharmacovigilance

\section{INTRODUCTION}

An adverse drug reaction (ADR), as per the WHO, is defined as "a response to a drug which is noxious and unintended, and which occurs at doses normally used in man for the prophylaxis, diagnosis, or for modification of physiological function." "These reactions pose a significant problem in view of increased morbidity and mortality, increasing costs of health care, and poor compliance. $^{2}$

The association of psychotropic medications with Adverse Drug Reactions (ADRs) is common and can occur even at the normal doses used in the management of acute and maintenance phases of psychiatric disorders. ${ }^{3}$ These ADRs can impair quality of life, may lead to poor medication adherence, cause physical morbidity, stigma, and in extreme cases, can be fatal. ${ }^{3}$ Common psychiatric disorders are anxiety disorders including panic disorder, obsessive-compulsive disorder, post-traumatic stress disorder, phobias, bipolar disorder, depression, mood disorders and psychotic disorders like schizophrenia. Many studies have reported the incidence, nature and occurrence of ADRs to various psychotropic medications. ${ }^{3-6}$ Previous studies has reported the incidence of ADRs range from $0.69 \%$ to $10.2 \%$ in patients visiting 
psychiatry outpatient departments. ${ }^{6-8}$ The awareness of the health care providers regarding ADRs of the psychotropic agents and how to manage them can foster the safe and rational use of these agents. Pharmacovigilance can play a vital role in alerting the healthcare providers from the possible ADRs and thus protecting the patients who are using psychotropic medications. ${ }^{9}$ In this context, Pharmacovigilance Programme of India (PvPI) has been launched since June 2010 with the objective to ensure safe use of drugs and generate ADR data in Indian patients. ${ }^{10}$

Psychotropic drugs are being increasingly used in this country owing to the growing incidence and prevalence of psychiatric disorders. There are a large number of ADRs associated with the use of psychiatric medications owing to their effect on multiple dopaminergic pathways as well. However, there is a lack of data on the exact incidence and magnitude of the problem in Indian setting. Hence, an attempt has been made in this study to analyse the clinical spectrum of ADRs and assess seriousness, causality, severity, and preventability of the ADRs reported in Psychiatric Department, BJ Medical College, Ahmedabad, Gujrat, India.

\section{METHODS}

The Department of Pharmacology, BJ Medical College, Ahmedabad, Gujrat, India has been working as ADR Monitoring Centre (AMC) under pharmacovigilance programme of India since 2010. All suspected Adverse Drug Reactions (ADRs) reported or notified by treating consultants of various departments of Civil Hospital Ahmedabad, Gujrat, India were collected in CDSCO approved spontaneous adverse drug reaction reporting form. ${ }^{11}$ All reported ADRs were collected at AMC and analysed for causality and then sent to National
Coordinating Centre via "Vigiflow". Psychiatry department has been actively reported ADRs since programme started. All adverse reactions reported in psychiatry patients were identified from this database (January 2011 to January 2017). Information regarding demographic details, adverse event, suspected drugs, concomitant drugs, laboratory investigation were collected and entered in Microsoft Excel Sheet 2017. Causality for each suspected drug was assessed by using the WHO UMC scale and Naranjo's algorithm. ${ }^{12,13}$ Severity of each ADR was assessed using modified Hartwig and Siegel scale whereas preventability of each ADR was assessed using modified Schumock and Thornton scale. ${ }^{14,15}$

\section{RESULTS}

A total 4368 Adverse Drug Reactions (ADRs) were reported during period between January 2011 to June 2017 at ADR monitoring centre. Out of which, 658 (15.06\%) ADRs were reported in psychiatric patients.

\section{Demographic details}

The mean age of psychiatric patients having ADRs was $38 \pm 13.34$ years. Most common age group was $36-65$ years $(49.39 \%)$ followed by $18-35$ years $(42.25 \%)$. Men $(57.3 \%)$ were more affected than women $(42.7 \%)$ with ratio of 1.34:1. Implicated drugs were most commonly prescribed for depression (26.1\%) followed by schizophrenia (15.2\%) and bipolar mood disorder (12.9\%).

\section{System-organ involvement}

Author observed 108 different types of psychiatric ADRs belonged to fifteen different organ systems (Figure 1).

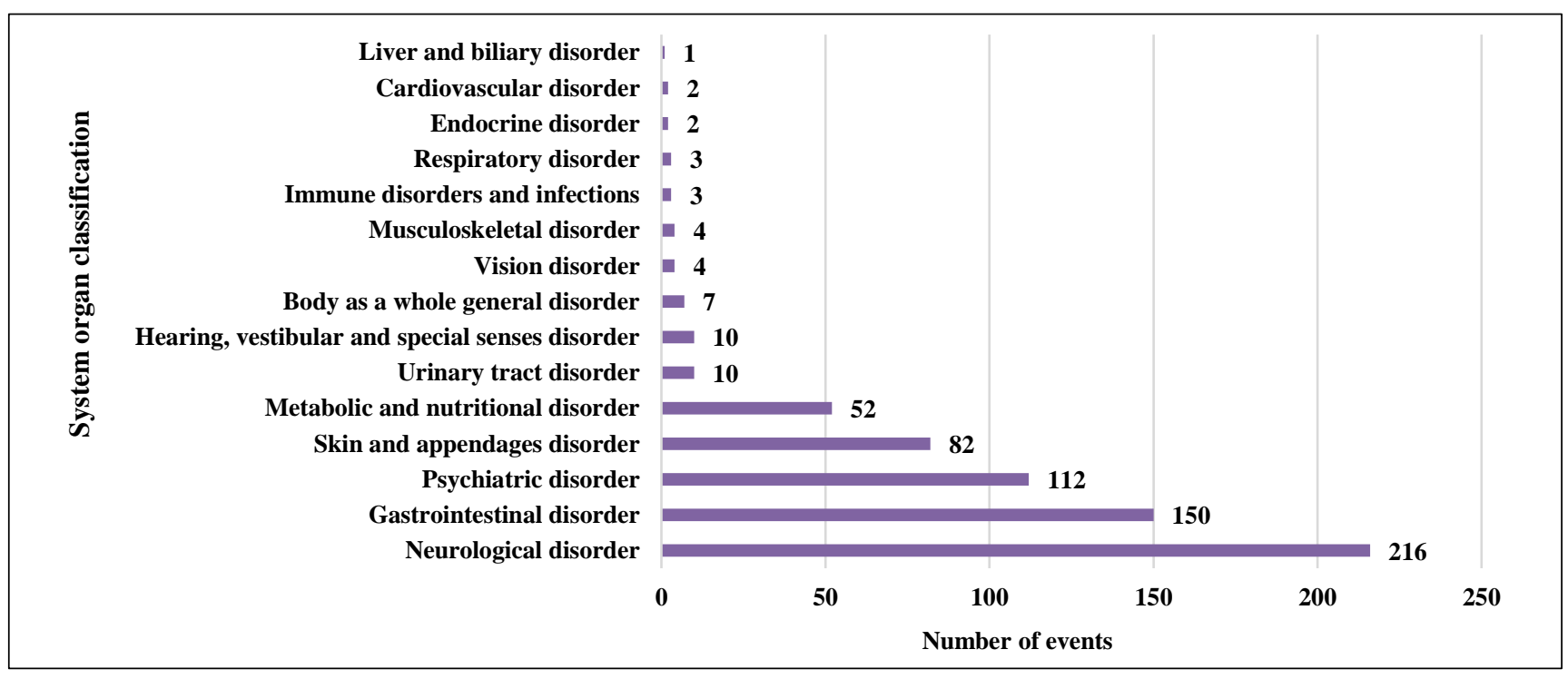

Figure 1: System organ classification of ADRs observed in psychiatric patients at a tertiary care hospital (n=658). 
Most commonly involved organ system was central nervous system $(216,32.82 \%)$ followed by gastrointestinal system $(150,22.79 \%)$ and psychiatric disorder (112, $17.02 \%$ ) (Figure 1). According to causal drug group, ADRs of gastrointestinal disorder $(84,38.4 \%)$ followed by psychiatric disorder $(60,27.4 \%)$ were more common with antidepressant drugs (Table 3 ). While antipsychotic drugs caused more neurological ADRs $(73 ; 45.9 \%)$ followed by metabolic and nutritional disorder $(36,22.6 \%)$ (Table 2$)$. The commonly reported reactions were extrapyramidal movement disorders (91, tremors-73, Akathisia-7, tardive dyskinesia- 5, dystonia-6), weight gain (49), headache (46) constipation (42) and dry mouth (38).

\section{Time relationship of psychiatric ADRs with drug treatment}

Majority of ADRs (32.98\%) in psychiatry patients were observed after one week to one month of starting drug treatment (Figure 2).

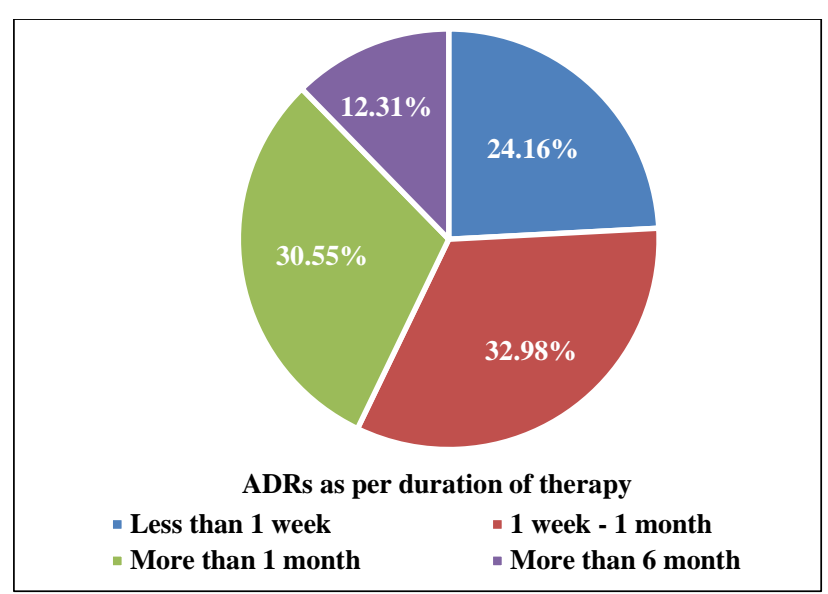

Figure 2: Temporal relationship of ADRs observed in psychiatric patients at a Tertiary care hospital $(\mathbf{n}=658)$.

Table 1: Pattern of ADRs observed in different group of antidepressant drugs used in psychiatric patients $(n=219)$.

\begin{tabular}{|c|c|c|c|}
\hline Parameter & Serotonin reuptake inhibitors & Tricyclic antidepressant & Others (SNRIs, NaSSAs) \\
\hline No. of ADR & $115(52.5 \%)$ & $84(38.4 \%)$ & $20(9.1 \%)$ \\
\hline \multirow{5}{*}{$\begin{array}{l}\text { Most } \\
\text { common } \\
\text { ADRs }\end{array}$} & $\begin{array}{l}\text { Headache (Sertraline,11) } \\
\text { (Fluoxetine,5) }\end{array}$ & \multirow{2}{*}{$\begin{array}{l}\text { Dry mouth } \\
\text { (Amitriptyline,16) } \\
\text { (Imipramine,10) }\end{array}$} & \multirow[t]{2}{*}{ Nausea (Desvenlafexine) } \\
\hline & Insomnia (Fluoxetine, 12) & & \\
\hline & Diarrhoea (Fluoxetine,9) & $\begin{array}{l}\text { Constipation (Amitriptyline, } 7 \text { ) } \\
\text { (Imipramine, } 12 \text { ) }\end{array}$ & \multirow{3}{*}{ Drowsiness (Venlafexine) } \\
\hline & Dizziness (Sertraline,6) & Headache- 9 & \\
\hline & Nausea - 8 & Sedation - 6 & \\
\hline \multirow{9}{*}{$\begin{array}{l}\text { Most } \\
\text { common } \\
\text { SOC }\end{array}$} & Psychiatric disorder (39) & Gastrointestinal disorder (48) & Psychiatric disorder (10) \\
\hline & Gastrointestinal disorder (30) & Neurological disorder (14) & $\begin{array}{l}\text { Gastrointestinal disorder } \\
\text { (6) }\end{array}$ \\
\hline & Neurological disorder (29) & Psychiatric disorder (11) & Neurological disorder (3) \\
\hline & Skin and appendages disorder (16) & Metabolic and nutritional disorder (4) & \multirow{6}{*}{$\begin{array}{l}\text { Metabolic and nutritional } \\
\text { disorder (1) }\end{array}$} \\
\hline & \multirow{5}{*}{ Respiratory disorder (1) } & Urinary tract disorder (2) & \\
\hline & & Vision disorder (2) & \\
\hline & & Skin and appendages disorder (1) & \\
\hline & & Immune disorders and infections (1) & \\
\hline & & Cardiovascular disorder (1) & \\
\hline \multirow{2}{*}{ Severity } & Mild (97) & Mild (83) & \multirow{2}{*}{ Mild (20) } \\
\hline & Moderate (18) & Moderate (01) & \\
\hline \multirow{2}{*}{$\begin{array}{l}\text { Preventabilit } \\
\mathrm{y}\end{array}$} & Not preventable (73) & Not preventable (74) & \multirow{2}{*}{$\begin{array}{l}\text { Not preventable (15) } \\
\text { Probably preventable (5) }\end{array}$} \\
\hline & Probably preventable (42) & Probably preventable (10) & \\
\hline \multirow{2}{*}{ Seriousness } & Serious (2) & Serious (1) & Serious $(0)$ \\
\hline & Non-serious (113) & Non-serious (83) & Non-serious (20) \\
\hline
\end{tabular}

SNRIs- Serotonin-norepinephrine reuptake inhibitor, NaSSas- Noradrenergic and specific serotonergic antidepressants.

ADRs of gastrointestinal disorders were commonly observed within one week of starting treatment, while ADRs of neurological disorders were more observed after one month to six months of initiation of treatment (Table
1). Gastrointestinal disorders $(70,31.9 \%)$ were most commonly seen within one-month therapy of antidepressant medication while psychiatric events (16, $7.3 \%$ ) were commonly seen after one month of therapy. In 
case of antipsychotic medication neurological disorder (67, $42.14 \%$ ) were commonly observed within six months of therapy while metabolic and nutritional disorders $(9,5.7 \%)$ were commonly seen after six months of therapy.

\section{Causal drug groups}

A total 44 drugs were responsible for 658 psychiatric ADRs. The most common causal drug groups were antidepressant group (29.48\%) followed by antipsychotics (23.12\%) and antiepileptics (18.96\%) (Figure 3).

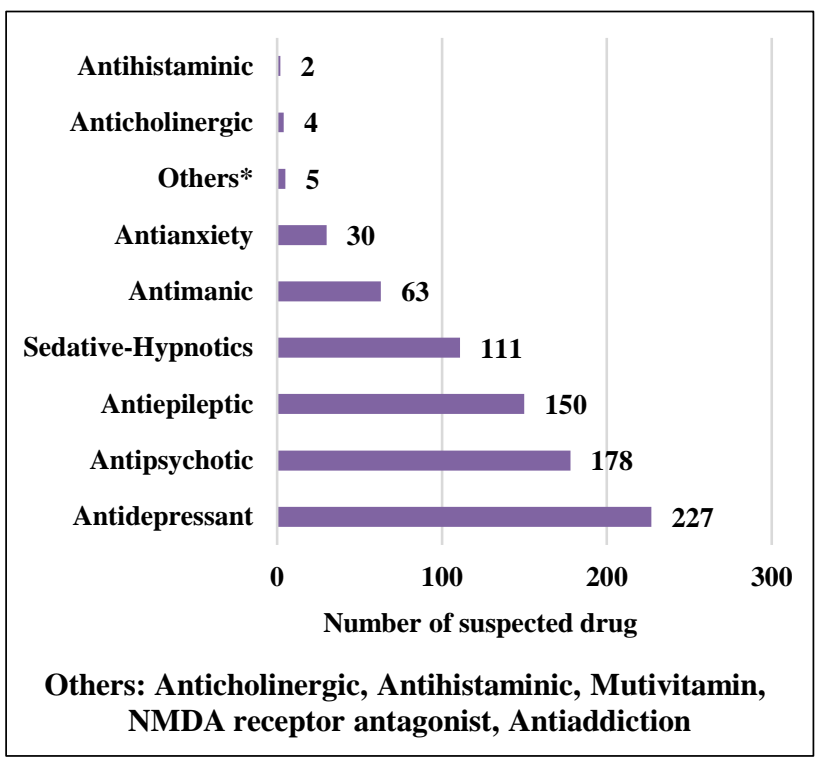

Figure 3: Suspected causal drug groups for ADRs observed in psychiatric patients at a tertiary care hospital $(n=658)$.

SSRIs (Selective serotonin reuptake inhibitors) and atypical antipsychotics were the most common causal drug subgroup in antidepressants and antipsychotics respectively. Overall most common drug implicated for ADRs were fluoxetine (10\%), lithium (8.2\%), olanzapine (7.9\%) followed by phenytoin $(7.4 \%)$. Fluoxetine was most common causal drug in SSRI subgroup, while Olanzapine was most common causal drug in atypical antipsychotic subgroup.

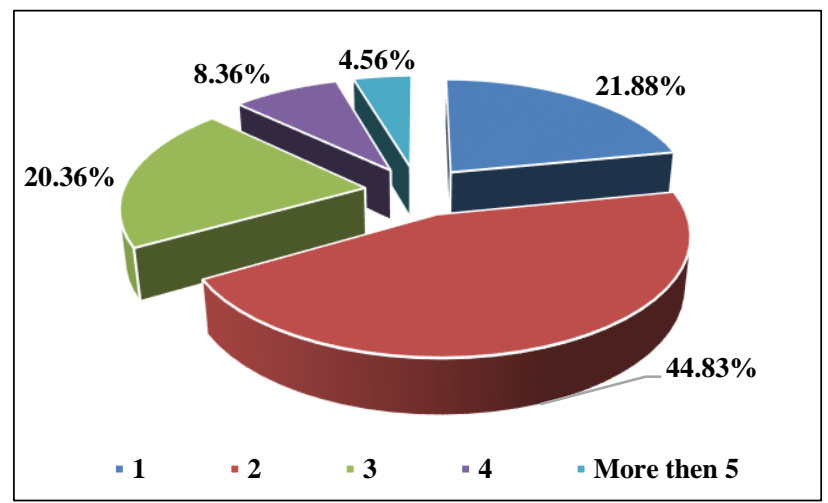

Figure 4: Average number of drugs prescribed in psychiatric patient having ADRs at a Tertiary care hospital $(n=658)$.

Table 2: Pattern of ADRs observed in different group of antipsychotic drugs used in psychiatric patients $(\mathbf{n}=159)$.

\begin{tabular}{|lll|}
\hline Parameter & Atypical antipsychotic & Typical antipsychotic \\
\hline Number of ADR & $107(67.3 \%)$ & $52(32.7 \%)$ \\
\hline \multirow{3}{*}{ Most common ADRs } & Weight gain (Olanzapine, 21) & Tremors (Haloperidol,16) \\
\cline { 2 - 3 } & Tremors (Aripiprazole,4) & Constipation (Chlorpromazine,7) \\
\cline { 2 - 3 } & Hypersalivation (Olanzapine,4) & Weight Gain (Chlorpromazine, 4) \\
\cline { 2 - 3 } & Dizziness (Olanzapine,4) & Neurological disorders (30) \\
\hline \multirow{3}{*}{ Most common SOC } & Neurological disorders (43) & Gastrointestinal disorders (15) \\
\cline { 2 - 3 } & Metabolic and nutritional disorder (32) & Psychiatric disorders (3) \\
\cline { 2 - 3 } & Gastrointestinal disorders (15) & Metabolic and nutritional disorder (4) \\
\cline { 2 - 3 } & Psychiatric disorders (12) & Mild (40) \\
\cline { 2 - 3 } & Urinary tract disorder (3) & Moderate (12) \\
\cline { 2 - 3 } & Cardiovascular disorder (1) & Not preventable (51) \\
\cline { 2 - 3 } & Musculoskeletal disorders (1) & Probably preventable (1) \\
\hline \multirow{2}{*}{ Severity } & Mild (94) & Serious (2) \\
\hline \multirow{2}{*}{ Preventability } & Moderate (13) & Non-serious (50) \\
\hline Seriousness & Not preventable (103) & \\
\hline
\end{tabular}


Table 3: Analysis of observed ADRs as per duration of therapy in psychiatric patients at a Tertiary care hospital $(\mathbf{n}=658)$.

\begin{tabular}{|c|c|c|c|c|}
\hline Parameter & Less than one week & 1 week to 1 month & 1 month to 6 months & More than 6 months \\
\hline $\begin{array}{l}\text { Number of } \\
\text { ADRs }\end{array}$ & $159(24.2 \%)$ & $217(32.9 \%)$ & $201(30.54 \%)$ & $81(12.3 \%)$ \\
\hline \multirow{12}{*}{$\begin{array}{l}\text { Most } \\
\text { common } \\
\text { SOC }\end{array}$} & $\begin{array}{l}\text { Gastrointestinal disorder } \\
(53)\end{array}$ & $\begin{array}{l}\text { Neurological disorder } \\
(66)\end{array}$ & $\begin{array}{l}\text { Neurological disorder } \\
(75)\end{array}$ & $\begin{array}{l}\text { Neurological disorder } \\
(40)\end{array}$ \\
\hline & Neurological disorder (35) & $\begin{array}{l}\text { Gastrointestinal } \\
\text { disorder (53) }\end{array}$ & $\begin{array}{l}\text { Gastrointestinal } \\
\text { disorder(36) }\end{array}$ & $\begin{array}{l}\text { Metabolic and } \\
\text { nutritional disorder (15) }\end{array}$ \\
\hline & Psychiatric disorder (29) & $\begin{array}{l}\text { Psychiatric disorder } \\
(48)\end{array}$ & $\begin{array}{l}\text { Metabolic and } \\
\text { nutritional disorder (32) }\end{array}$ & $\begin{array}{l}\text { Gastrointestinal } \\
\text { disorder (8) }\end{array}$ \\
\hline & $\begin{array}{l}\text { Skin and appendages } \\
\text { disorder }(25)\end{array}$ & $\begin{array}{l}\text { Skin and appendages } \\
\text { disorder (34) }\end{array}$ & $\begin{array}{l}\text { Psychiatric disorder } \\
(27)\end{array}$ & $\begin{array}{l}\text { Psychiatric disorder } \\
(8)\end{array}$ \\
\hline & $\begin{array}{l}\text { Hearing, vestibular and } \\
\text { special senses disorder (9) }\end{array}$ & $\begin{array}{l}\text { Metabolic and } \\
\text { nutritional disorder (4) }\end{array}$ & $\begin{array}{l}\text { Skin and appendages } \\
\text { disorder (18) }\end{array}$ & $\begin{array}{l}\text { Skin and appendages } \\
\text { disorder (5) }\end{array}$ \\
\hline & Respiratory disorder (3) & $\begin{array}{l}\text { Urinary tract disorder } \\
\text { (4) }\end{array}$ & $\begin{array}{l}\text { Urinary tract disorder } \\
\text { (4) }\end{array}$ & Vision disorder (2) \\
\hline & Urinary tract disorder (2) & $\begin{array}{l}\text { Body as a whole } \\
\text { general disorder ( } 3 \text { ) }\end{array}$ & $\begin{array}{l}\text { Body as a whole } \\
\text { general disorder (4) }\end{array}$ & Endocrine disorder (1) \\
\hline & $\begin{array}{l}\text { Immune disorders and } \\
\text { infections (1) }\end{array}$ & $\begin{array}{l}\text { Liver and biliary } \\
\text { disorder (1) }\end{array}$ & Endocrine disorder (1) & $\begin{array}{l}\text { Immune disorders and } \\
\text { infections (1) }\end{array}$ \\
\hline & $\begin{array}{l}\text { Metabolic and nutritional } \\
\text { disorder (1) }\end{array}$ & $\begin{array}{l}\text { Musculoskeletal } \\
\text { disorder (1) }\end{array}$ & $\begin{array}{l}\text { Hearing, vestibular and } \\
\text { special senses disorder } \\
\text { (1) }\end{array}$ & $\begin{array}{l}\text { Musculoskeletal } \\
\text { disorder (1) }\end{array}$ \\
\hline & \multirow{3}{*}{$\begin{array}{l}\text { Musculoskeletal disorder } \\
\text { (1) }\end{array}$} & Vision disorder (1) & $\begin{array}{l}\text { Musculoskeletal } \\
\text { disorder (1) }\end{array}$ & \\
\hline & & $\begin{array}{l}\text { Cardiovascular } \\
\text { disorder (1) }\end{array}$ & Vision disorder (1) & \\
\hline & & $\begin{array}{l}\text { Immune disorders and } \\
\text { infections (1) }\end{array}$ & $\begin{array}{l}\text { Cardiovascular } \\
\text { disorder (1) }\end{array}$ & \\
\hline
\end{tabular}

Among antidepressants drugs, $60.8 \%$ of ADRs were caused by newer antidepressants like SSRIs, SNRIs (Serotonin-norepinephrine reuptake inhibitor), NaSSAs (Noradrenergic and specific serotonergic antidepressant).

Among antipsychotic group of drugs, $70.2 \%$ of ADRs were caused by atypical antipsychotic drugs. Most commonly observed reactions with atypical antipsychotics, typical antipsychotics, SSRIs and tricyclic antidepressants are presented in Table 2 and Table 3.

Majority of patients reported ADRs were on more than two drugs (33.28\%) (Figure 4).

\section{Causality assessment, severity and preventability}

WHO-UMC causality assessment showed possible relationship $(77.01 \%)$ with drugs followed by probable $(22.72 \%)$, while Naranjo's algorithm showed possible relationship $(54.25 \%)$ followed by probable $(62.76 \%)$ as per Naranjo's algorithm.
Most of the psychiatric ADRs $(635,96.5 \%)$ were nonserious and continuing at the time of reporting. Serious ADRs in this study includes SJ Syndrome (6), erythema multiforme (2), hypothyroidism (2), breathlessness (2), hyponatremia (1), toxic epidermal necrolysis (1). Commonly implicated drugs for the serious ADRs were phenytoin (6), lithium (2), valproate (2), carbamazepine (2), lamotrigine (1) clonazepam (1). Majority of the psychiatric ADRs were mild in severity $(548,83.28 \%$ ) while $(98,14.9 \%)$ were moderate and $(12,1.8 \%)$ were severe in nature. Although majority of the psychiatric ADRs were not preventable (77.36\%) while 149 (22.64\%) were probably preventable.

\section{DISCUSSION}

Due to long term treatment in psychiatric patients, compliance to the treatment is a major issue. Further, adverse reactions because of medication used in psychiatric patients may hamper the compliance and lead to more economic burden also. 
Hence, this study was conducted to evaluate the pattern of adverse drug reaction observed by spontaneous method in psychiatric patients.

In this study, male $(57.3 \%)$ were affected more with ADRs than female $(42.7 \%)$ with male:female ratio 1.34 . In other studies, conducted by Lucca JM et al, Sridhar SB et al, and Sengupta G et al, observed male predominance with male:female ratio $1.05,1.02$, and 2.19 respectively. ${ }^{3,16,17}$

Mean age of patients in this study was 37.88 year which is comparable to a study conducted by Sengupta B et al, (34.4 years), Lucca JM et al, (35.6 years), Patel TK et al, (39.31 years) and Sridhar SB et al, (36.15 years). ${ }^{3,16-18}$ This finding may be because of high prevalence of psychiatric illness in this age group. ${ }^{19}$

Most common indication for psychiatric drugs in this study was depression (26\%), followed by schizophrenia (15.2\%), bipolar mood disorder (12.9\%) and epilepsy (12.9\%). Similarly, a study conducted by Sridhar SB et al, in psychiatric outpatients in UAE found depression (24.1\%) was most common indication followed by obsessive compulsive disorder $16.07 \%$, epilepsy (13.39\%) and schizophrenia (11.6\%). ${ }^{17}$ Patel TK et al, analysed spontaneous ADRs reported at Department of psychiatric at Gujarat found schizophrenia was leading indication followed by depression. ${ }^{18}$ An observational study conducted in Psychiatric OPD by Sengupta G et al, in Kolkata found bipolar affective disorder (27\%), schizophrenia (24\%) followed by depression (22\%) were common indication for drug treatment. ${ }^{3}$

Most common system organ class involved in this study was neurological disorder $(32.82 \%)$, gastrointestinal disorder $(22.79 \%)$ followed by psychiatric disorder $(17.02 \%)$. Similar results were observed in Sridhar SB et al, study in which most common SOC was CNS disorders (29.5\%) followed by gastrointestinal disorder $(23.2 \%) .{ }^{17} \mathrm{~A}$ study done by Patel TK et al, observed CNS disorder was most common SOC involved because of psychiatric medications. $^{18}$

Most common presentation of ADR in this study was tremors $(11.09 \%)$, followed by weight gain $(7.45 \%)$, headache $(6.99 \%)$, and constipation $(6.38 \%)$. Similar result was observed by Sengupta $\mathrm{G}$ et al, study in which tremors $(19.6 \%)$ was most common followed by weight gain (15.34\%), constipation $14.49 \% .^{3}$ Overall extra pyramidal symptoms $(13.8 \%)$ were most common in this study, which is similar in Patel TK et al, study $21(21.6 \%) .{ }^{18}$

In this study, antidepressant $(29.48 \%)$ was most common suspected causal drug group followed antipsychotic $(23.12 \%)$, antiepileptic $(19.48 \%)$, and sedative hypnotic (14.42\%). Similarly, a Brazilian study and Patel TK et al, study analysed spontaneous ADRs and found antidepressant was commonest causal group. ${ }^{18}$ This finding could be explained by prevalence of depression is more than other psychiatric disorders. ${ }^{20}$ In contrast to above studies, Sridhar SB et al, and Sengupta G et al, found atypical antipsychotic was most common suspected drug group. ${ }^{3,17}$

Most common drug implicated for ADRs in this study were fluoxetine $(10 \%)$, lithium $(8.2 \%)$, olanzapine $(7.9 \%)$ followed by phenytoin (7.4\%). Similarly, escitalopram was most common causal drug observed in Patel TK et al, followed by olanzapine. ${ }^{18}$ Sridhar SB et al, found escitalopram (14.2\%) was common causal drug followed by quetiapine $(11.6 \%)$ and olanzapine $(8.9 \%)$ while Sengupta $\mathrm{G}$ et al, study observed olanzapine (31.82\%) as most common antipsychotic drug followed by haloperidol $(19.03 \%) .^{3,17}$

Causality assessment by WHO UMC shows possible category $593(77.01 \%)$, probable category $175(22.73 \%)$ and one in each certain and unlikely category. Similarly, Sridhar SB et al, study found more possible (45.5\%) causal relationship followed by probable $(34.9 \%)$ and certain (14.3\%). ${ }^{17}$ In contrast, Sengupta $\mathrm{G}$ et al, study found higher probable $(92.9 \%)$ causal relationship than possible $(7.1 \%)$ and Patel TK et al, study found probable (55.67\%), possible $(43.3 \%)$, certain $(1.03 \%) .^{3,18}$ Above findings suggest possible relationship is most common which could be explained by usage of more than one drug or other alternative cause may be responsible for ADR and dechallenge may be not done because of mild nature of ADR.

Most of the ADRs (83.28\%) in this study were mild in nature followed by moderate $(14.89 \%)$ and severe $(1.82 \%)$ which is similar to Sridhar SB et al study. ${ }^{17}$ Most of ADRs $(77.36 \%)$ were not preventable followed by probably preventable $(22.64 \%)$. Similarly, Sridhar SB et al, study found $82.1 \%$ of ADRs were not preventable followed by probably preventable (15.2\%), definitely preventable $(2.7 \%) .{ }^{17}$ Above findings suggests that most of ADRs are not preventable and mild in nature. Hence, proper counselling of patients and caretakers regarding ADRs before starting treatment may improve compliance therapy for long time.

Antidepressant and antipsychotic drug group were also separately analysed. In antidepressant group, most common system organ class affected were gastrointestinal disorder 84 (38.36\%), psychiatric disorder 60 (27.39\%), neurological disorder $46(21 \%)$ followed by skin and appendages disorder $17(7.8 \%)$ which is similar to study done by Patel TK et al, and Lucca JM et al. ${ }^{16,18}$ Dry mouth was most common ADR in antidepressant group which is similar to Lucca JM et al, study. ${ }^{16}$ SSRI was most common causal drug subgroup followed TCA among antidepressants. Similarly, Lucca JM et al, found most common drug class for ADRs were SSRI (53.92\%), NASSAs $(26.96 \%)$ followed by TCA $(15.19 \%) .{ }^{16}$ Because SSRIs are known to cause less side effects than TCA, SSRI replaces TCA in most of conditions. Hence, more usage of newer antidepressants like SSRI explain above finding observed in different studies. In antipsychotic drug group, olanzapine $(48.8 \%)$ was most common suspected drug 
followed by risperidone (27.2\%) and aripiprazole (9.6\%) in this study. Similarly, Piparva KG et al, study analysed ADRs of atypical antipsychotic and found most common drug suspected were olanzapine $(47.13 \%)$, risperidone $(36.55 \%)$ followed by clozapine $(10.7 \%) .{ }^{21}$ Weight gain was most common presentation in antipsychotic group followed by tremors, hypersalivation and dizziness. In study done by Piparva KG et al, shows most common presentation was weight gain followed by increased appetite, followed by dizziness. ${ }^{21}$

\section{CONCLUSION}

In this study, lack of routine haematological and clinical chemistry (e.g., blood sugar, lipids) reports were not mentioned in CDSCO forms which may lead to underreporting of metabolic disturbance because of antipsychiatric drug. Underreporting, lack of information about substituted drugs or treatment of ADRs, lack of information on recently introduced drugs and single centre are also other limitations of this study. Although this study cannot provide true incidence or prevalence data, it offers a representative idea of the ADR profile of psychiatric drugs likely to be encountered in OPD patients in an Indian hospital. Constant vigil in detecting ADRs and subsequent dose adjustments can make therapy with psychiatric drugs safer and more effective. This, in turn, should improve compliance. Such database of ADRs occurred by psychiatric drugs can provide early warning signals of drug reaction links if kept under active surveillance.

\section{Funding: No funding sources}

Conflict of interest: None declared

Ethical approval: The study was approved by the Institutional Ethics Committee

\section{REFERENCES}

1. WHO Meeting on International Drug Monitoring: the Role of National Centres (1971: Geneva, Switzerland) and World Health Organization. (1972). International drug monitoring : the role of national centres, report of a WHO meeting [held in Geneva from 20 to 25 September 1971]. World Health Organization. Available

at: http://www.who.int/iris/handle/10665/40968.

2. Haddad PM, Sharma SG. Adverse effects of atypical antipsychotics. CNS Drugs. 2007;21(11):911-36.

3. Sengupta G, Bhowmick S, Hazra A, Datta A, Rahaman M. Adverse drug reaction monitoring in psychiatry out-patient department of an Indian teaching hospital. Ind J Pharmacol. 2011;43(1):36.

4. Prajapati HK, Joshi ND, Trivedi HR, Parmar MC, Jadav SP, Parmar DM, et al. Adverse drug reaction monitoring in psychiatric outpatient department of a tertiary care hospital. Depression. 2013;63:15-48.

5. MiShra S, Swain TR, Mohanty M. Adverse drug reaction monitoring of antidepressants in the psychiatry outpatients department of a tertiary care teaching hospital. J Clin Diagn Res JCDR. 2013;7(6):1131.

6. Solanke B, Mahatme MS, Dakhale G, Hiware S, Shrivastava M, Waradkar P. Adverse drug reaction pro le at psychiatry out-patient department of a tertiary referral centre in Central India. Int $\mathbf{J}$ Basic Clin Pharmacol. 2013;2:341-3.

7. Pahari NI, Tripathi SK, Maity TA, Gupta BK, Bagchi $\mathrm{CH}$, Mondal DK. Evaluation and analysis of adverse drug reactions of second generation antipsychotics in a psychiatry out-patient department. Int J Pharm Pharm Sci. 2012;4:158-62.

8. Thomas M, Boggs AA, DiPaula B, Siddiqi S. Adverse drug reactions in hospitalized psychiatric patients. Ann Pharmacotherapy. 2010;44(5):819-25.

9. Faich GA. US adverse drug reaction surveillance 1989-1994. Pharmacoepidemiol Drug Safety. 1996;5(6):393-8.

10. Lihite RJ, Lahkar M. A study on cutaneous adverse drug reactions in ADR monitoring centre of tertiary care hospital, Guwahati. J Applied Pharmaceut Sci. 2013;3(3):78.

11. Adverse drug reaction reporting form: Central Drugs Standard Control Organization Directorate General of Health Services, Ministry of Health and Family Welfare Available at: http://www.cdsco.nic.in/writereaddata/ADR\%20form $\% 20$ PvPI.pdf.

12. The use of the WHO-UMC system for standardised case causality assessment. Available at: https://www.who.int/medicines/areas/quality_safety/s afety_efficacy/WHOcausality_assessment.pdf.

13. Naranjo CA, Busto U, Sellers EM, Sandor P, Ruiz I, Roberts EA, et al. A method for estimating the probability of adverse drug reactions. Clin Pharmacol Therapeutics. 1981;30(2):239-45.

14. Hartwig SC, Siegel J, Schneider PJ. Preventability and severity assessment in reporting adverse drug reactions. Am J Heal Sys Pharmacy. 1992;49(9):222932.

15. Schumock GT, Thornton JP. Focusing on the preventability of adverse drug reactions. Hospital Pharmacy. 1992;27(6):538.

16. Lucca JM, Madhan R, Gurumurthy P, Dushad R. A prospective observational study to evaluate safety reporting of antidepressants at a tertiary care hospital in India. Ind J Pharmacol. 2014;46(5):543.

17. Sridhar SB, Al-Thamer SS, Jabbar R. Monitoring of adverse drug reactions in psychiatry outpatient department of a Secondary Care Hospital of Ras Al Khaimah, UAE. J Basic Clin Pharmacy. 2016;7(3):80.

18. Patel TK, Bhabhor PH, Desai N, Shah S, Patel PB, Vatsala E, et al. Adverse drug reactions in a psychiatric department of tertiary care teaching hospital in India: Analysis of spontaneously reported cases. Asian J Psychiatry. 2015;17:42-9.

19. Murthy RS. National mental health survey of India 2015-2016. Ind J Psychiatry. 2017;59(1):21.

20. World Health Organization. Depression and other common mental disorders: global health estimates. 
World Health Organization, 2017. Available at: http://www.who.int/iris/handle/10665/254610.

Accessed 25 March 2017.

21. Piparva KG, Buch JG, Chandrani KV. Analysis of adverse drug reactions of atypical antipsychotic drugs in psychiatry OPD. Ind $\mathrm{J}$ Psychol Med. 2011;33(2):153.
Cite this article as: Barvaliya S, Panchal JR, Desai MK, Parikh M. Pattern of adverse drug reactions into psychiatric patients. Int $\mathrm{J}$ Basic Clin Pharmacol 2019;8:1059-66. 